\title{
Smoking Behaviour of University Students: a Descriptive Study
}

\author{
SUHÁNYI, L. ', GAVUROVÁ, B. ${ }^{2}$, IVANKOVÁ, V. ${ }^{3}$, RIGELSKÝ, M. ${ }^{4}$
}

1 | University of Prešov, Faculty of Management, Prešov, Slovak Republic

2 Tomas Bata University, Faculty of Management and Economics, Centre for Applied Economic Research, Zlín, Czech Republic

3| University of Prešov, Faculty of Management, Department of Economics and Economy, Prešov, Slovak Republic

4 | University of Prešov, Faculty of Management, Department of Marketing and International Trade, Prešov, Slovak Republic
Citation | Suhányi, L., Gavurová, B., Ivanková, V., Rigelský, M. (2020). Smoking Behaviour of University Students: a Descriptive Study. Adiktologie, 20(1-2), 57-63; doi 10.35198/01-2020-001-0009.
BACKGROUND: The theoretical background of the study shows the importance of the issue of smoking behaviour, especially in the case of students. Despite the declining trend of smoking in recent decades, it is still one of the leading causes of death, disease, and mental disorders worldwide. AIM: The main objective of the study is to evaluate the incidence of smoking in the population of university students in the territory geographically determined by the Slovak Republic.

DESIGN AND MEASUREMENTS (METHODS): The data was obtained by questioning and the collection itself was carried out via an electronically distributed questionnaire in 2020. Frequency analysis and Pearson's $X 2$ test were used to meet the above-mentioned objective. SAMPLE (PARTICIPANTS): The sampling can be characterized by a combination of selection based on voluntariness and availability, and after that quota selection was applied to complete the representativeness of the sample. Excluding the invalid observations, the sample consists of 1612 responses of students of Slovak universities.
The analyses included the identification variables (Gender, Degree of Study, Year of Study, Form of Study, Residence - home, Residence - school), also included the dichotomous variable determining smoking and the Glover-Nilsson Smoking Behavioural Questionnaire (GNSBO) scale. RESULTS: In general, from the results it can be seen that about one-third of the students (36.36\%) are smokers. Using the GNSBO scale, Mild Addiction was observed in $55.06 \%$ of cases, followed by Moderate Addiction (33.16\%) and Strong Addiction (10.82\%), and the smallest group of smokers showed Very Strong Addiction $(0.94 \%)$. Looking at the differences between smokers and non-smokers, as well as at the differences between the chosen identification variables in the GNSBO categories of smokers, it is not possible to speak of differences that would clearly distinguish a smoker from a non-smoker. CONCLUSIONS: One of the riskiest periods of life in terms of acquiring smoking habits is the period of studying at university. Prevention and awareness of the harmful effects of smoking is therefore necessary for students.

\section{Keywords | Smoking Behaviour - Addiction - Glover-Nilsson Smoking Behavioural Questionnaire (GNSBO) - Students - Inequalities - Slovakia}

\footnotetext{
Grant affiliation | This research was supported by the Internal Grant Agency of FaME Tomas Bata University in Zlin: RV0/2020: “Economic quantification of marketing processes that focus on value increase for a patient in a process of system creation to measure and control efficiency in health facilities in the Czech Republic".
} 


\section{INTRODUCTION AND THEORETICAL BACKGROUND}

Smoking is currently one of the most discussed topics. It can be said that every person encounters this phenomenon every day, without exception. Each of us is a smoker in his or her own way. The only difference is that some people smoke actively and some passively, or, so to speak, unintentionally. Looking at active smokers in Slovakia, according to Eurostat statistics, Slovakia is one of the countries with a higher level of smoking. What can be evaluated positively is that only a small percentage of the population of smokers smokes more than 20 cigarettes per day (Eurostat, 2020). The World Bank database states that the prevalence of smoking in the population of Slovakia aged over 15 years old is declining slightly and it is estimated that $35.1 \%$ of the population were smokers in 2016 , which is currently the last available year in the database. It is obvious that a higher proportion of smokers are men, but what can be evaluated as alarming information is the rising trend in the level of cigarette smoking in the case of women, while for men it is a declining trend (World Bank, 2020).

Tobacco leaf smoking was first introduced by the American Huron Indians, who smoked tobacco leaves during their religious prayer ceremonies. Tobacco is not mentioned at all in written history before the discovery of America (Zeuske, 2016). It was first offered to Columbus by the natives of the Caribbean. Tobacco exports ensured the survival of Jamestown, the American Revolution was financed by the tobacco business, and the first American presidents (George Washington and Thomas Jefferson) were tobacco growers. Not so long ago, Hollywood used cigarettes as a symbol of romance, charm, and masculinity. US (United States) troops gave them to people they met in countries where they fought, and after the Second World War cigarettes were used as a payment instrument instead of money in all the territories from Paris to Beijing. In the $21^{\text {st }}$ century, tobacco has been experiencing a great popularity, especially in developing countries and in the former Eastern European bloc. Smoking is still the number one cause of mortality worldwide. The statistics presented by the public media speak for themselves: cigarette smoke causes the death of more people than the sum of all deaths resulting from all kinds of violence, including accidents, crime, and suicides.

At this point, it is important to distinguish nicotine addiction from smoking behaviour. While smoking behaviour is an objective measure of tobacco consumption, nicotine addiction is a latent construct that indicates the extent of psychological and physiological addiction to nicotine (Fagerstrom, 2003; Shiffman et al., 2004; Branstetter et al., 2020).

Smoking is a repetitive behaviour enacted under fluctuating situational and personal conditions (Berli et al., 2015; Doran et al., 2007; Ferguson et al., 2009; Shiffman et al., 2007; Yuan et al., 2018). It can be emphasized that in the United States about 443,000 people die each year as a result of tobacco-related diseases, while another 8.6 million people live with serious diseases caused by smoking. It should also be noted that the prevalence of tobacco use among adults has decreased in recent years, but tobacco consumption among teenagers and young adults tends to remain high (Jayawardhana et al., 2019). Another study, which was conducted in China and focused on the effect of smoking-related diseases, showed a significant decrease in the prevalence of smoking observed from 1990 to 2017 in both males and females, while confirming the long lagged effect of smoking and deaths, as the smoking-related death rates showed an increasing trend in both sexes during the study period (Wen et al., 2020). In general, smoking remains a major public health concern, as it is a leading cause of death and morbidity in almost every country (Ng et al., 2014; Braillon, 2017).

There are well-known health consequences of smoking tobacco. In addition, smoking has several implications from a biochemical point of view; nicotine increases cholinergic activity, increases the bioavailability of serotonin and dopamine, and exerts several neuroendocrine actions, among other effects (Greden \& Pomerleau, 1995). Additionally, Lawrence et al. (2013) states that there are two main causes that contribute to early deaths: the mental health condition and the smoking-related diseases. In this context, the bi-directional temporal relationship between smoking and depression can be underlined (Leventhal et al., 2011; Kendler et al., 1993; Bainter et al., 2020). According to the evidence of a study conducted among young adults in the United States, the increased risk of major depressive disorder associated with smoking can be reduced by quitting (Bakhshaie et al., 2015). The findings of Weinberger et al. (2020) showed a higher prevalence of smoking in people with depression than in those without depression. The authors also concluded that while daily smoking decreased among individuals both with and without depression, quit ratios were consistently lower in people with depression compared with those without depression. The transition from high school to college is very challenging for most fresh students. Because of difficulties in adjusting to the new environment and forming new social relationships, and being separated from close relationships, university students are more likely to feel lonely and depressed in their first academic year (Leshargie et al., 2019; Karadogan et al., 2018; Zhang et al., 2020).

Azagba et al. (2020) revealed the findings of a study on students in the United States from 2011 to 2018, according to which current young cigarette smokers smoked on fewer days and fewer cigarettes per day, and the age of the first use of cigarettes increased. Over time, however, young males smoked more heavily and started smoking earlier. Another study dealing with a research sample of people aged 11-26 years in Thailand from 1996 to 2015 also showed that the prevalence of smoking tended to decrease over time (Intarut et al., 2019). But there is a new phenomenon called e-cigarette smoking; the study of Azagba et al., (2020) showed that the use of electronic cigarettes among young people increased significantly from 2014 to 2018. For example, in 2018 in China, there were more than 371 million cigarette smokers and 12.6 million electronic cigarette users (Wen et al., 2020). Electronic cigarettes may have offset conventional smoking among adolescents and young adults 
by maintaining the total prevalence of nicotine use and diverting them from more harmful conventional smoking. In addition, e-cigarette users appear to be initiated at older ages compared to conventional smokers, which is associated with lower risk (Foxon \& Selya, 2020).

To reduce the prevalence of smoking requires multiple efforts and active steps that lead to improved smoking-related health education, an anti-cigarette trend, free access to smoking cessation counselling, and the implementation of regulations and restrictions on tobacco advertising, promotion, and sponsorship (Wen et al., 2020). For example, the findings provided by Septiono et al. (2020) showed that there may be an association between the adoption of local smokefree policies and decreased intensity of smoking. Within an overall decreasing trend of daily smoking in Sweden, Zhou et al. (2019) found that "pictorial warnings together with text warnings and referral text" had a clear positive effect on the calling rates to the smoking quitline in the country, which means that the level of interest in the cessation of smoking increased significantly as a result of these interventions. The authors also revealed the effect of government interventions such as a campaign on passive smoking, a ban on smoking in restaurants, and an increase in the tobacco tax. In connection with the smoking behaviour of students, one of the possibilities is to introduce a school tobacco control policy. The findings of Jayawardhana et al. (2019) indicate that a school tobacco control policy that focuses on both students and school employees is associated with a reduced likelihood of smoking initiation among young people, but does not have much effect on young people becoming regular smokers.

All these findings support research activities on the issue of smoking, which can clarify the current situation and help create prevention programmes. On this basis, the purpose of this study is to provide a picture of smoking behaviour among students in the conditions of the Slovak Republic. Identifying the current situation is considered an important step in reducing this negative pattern of behaviour.

\section{METHODOLOGY}

As mentioned in the previous section, smoking represents an unhealthy lifestyle that is currently being criticized by society. Therefore, the main objective of the study is to evaluate the incidence of smoking in the population of university students in the territory geographically determined by the Slovak Republic.

This objective was achieved through analytical procedures. The part of the population of students who smoke was defined. Subsequently, smokers were divided on the basis of their Glover-Nilsson Smoking Behavioural Questionnaire (GNSBQ) score into groups of smoking-related behaviour. At this point, it is appropriate to state that the GNSBQ questionnaire is an internationally used tool for determining the intensity of smoking regarding the behavioural dimension of smoking. This tool has been verified by several rounds of validation in several countries.
In general, the GNSBQ can be considered a good tool for detecting nicotine-craving behaviour; it is used worldwide in research, as well as in clinical practice. The differences in selected smoking characteristics between selected variables identifying the respondent (Gender, Degree of Study, Year of Study, Form of Study, Residence - home, Residence - school) were also tested.

Sampling and data collection were carried out using a questionnaire distributed during the first half of 2020. The research was conducted on a population of students. The sampling was a combination of selection based on availability (voluntariness) and quota selection. The questionnaire included a control question asking the respondent for agreement with the statement that one million has six zeros (a numerical record was also provided); 98 observations were excluded from subsequent analytical processes on the basis of disagreement with this statement. The questionnaire also included questions examining the nationality of the respondents and their residence. The research was focused on Slovak students living in Slovakia, and thus respondents who did not fulfil the research criteria were excluded ( $\mathrm{n}=129)$. The last validation step performed on specific survey items excluded 13 respondents. Therefore, the sample consists of 1612 Slovak university students. Table 1 shows the characteristics of the sample.

A dichotomous variable was included in the analyses to determine whether the respondent had smoked cigarettes in the last three months. In the case of a 'yes' answer (the respondent had smoked) the use of the GNSBQ scale followed, which classified the respondent on the basis of the sum of the scores from the survey items, into one of the following groups: i - Mild, ii - Moderate, iii - Strong and iv - Very Strong Smoking. Frequency analysis methods and Pearson's $\chi^{2}$ distribution test were used for the analytical processing. Statistical processing was performed using the SPSS v. 26 program from IBM (Armonk, New York, US).

\section{RESULTS}

The following part of the present study describes the results of the analytical processes leading to the fulfilment of the main objective, which is to evaluate the incidence of smoking in the population of university students in the territory geographically determined by the Slovak Republic.

Figure 1 points to the fact that the vast majority of university students are non-smokers (they had not smoked in the last three months). Specifically, 1187 respondents (73.64\%) stated that they did not smoke, and approximately one-third of the respondents ( $n=425 ; 36.36 \%)$ were smokers. The answer to the question of whether or not there is a difference in the distribution of smoking behaviour among the university students by categories of selected variables is given in Table 2.

The Table shows the output of the non-parametric $\chi^{2}$ test, which proves if there is a difference in the distribution of se- 


\begin{tabular}{|c|c|c|}
\hline Identification & $\mathbf{n}$ & $\%$ \\
\hline \multicolumn{3}{|l|}{ Gender } \\
\hline Male & 584 & 36.2 \\
\hline Female & 1028 & 63.8 \\
\hline \multicolumn{3}{|l|}{ Degree of Study } \\
\hline 1st degree & 1099 & 68.2 \\
\hline 2nd degree & 412 & 25.6 \\
\hline Combined 1 st and 2 nd degree & 39 & 2.4 \\
\hline 3rd degree & 62 & 3.8 \\
\hline \multicolumn{3}{|l|}{ Year of Study } \\
\hline I. & 592 & 36.7 \\
\hline II. & 499 & 31.0 \\
\hline III. & 278 & 17.2 \\
\hline IV. & 102 & 6.3 \\
\hline V. & 131 & 8.1 \\
\hline VI. & 10 & 0.6 \\
\hline \multicolumn{3}{|l|}{ Form of Study } \\
\hline Full-time & 1496 & 92.8 \\
\hline Part-time & 116 & 7.2 \\
\hline \multicolumn{3}{|l|}{ Residence - home } \\
\hline Countryside & 794 & 49.3 \\
\hline City (up to 10,000 inhabitants) & 187 & 11.6 \\
\hline City $(10,001-100,000$ inhabitants) & 508 & 31.5 \\
\hline City $(100,001-1,000,000$ inhabitants $)$ & 123 & 7.7 \\
\hline \multicolumn{3}{|l|}{ Residence - school } \\
\hline College (Student Dormitory) & 673 & 41.7 \\
\hline Private accommodation & 133 & 8.3 \\
\hline With family & 63 & 3.9 \\
\hline With a friend/acquaintance & 10 & 0.6 \\
\hline I live at home & 733 & 45.5 \\
\hline
\end{tabular}

Table 1 | Frequency analysis - representativeness of the sample

\begin{tabular}{lccc}
\hline Identification & $\mathbf{x}$ value & df & p-value \\
\hline Gender & 0.05 & 1 & 0.817 \\
\hline Degree of study & 5.91 & 3 & 0.116 \\
\hline Year of study & 5.03 & 5 & 0.412 \\
\hline Form of study: & 1.40 & 1 & 0.236 \\
\hline Residence - home & 8.04 & 3 & 0.045 \\
\hline Residence - school & 10.34 & 4 & 0.035 \\
\hline
\end{tabular}

Table 2 | Distribution test of smoking between selected variables

lected variables between smoking students and non-smoking students (dichotomous variable with the YES/NO scale). These selected variables are the identifying characteristics of the respondents. On the basis of the results of the $\mathrm{p}$-value, it is concluded that a significant difference was confirmed only for the last two variables $\left(\chi^{2}\right.$ : Residence - home $=8.04$ (0.045); Residence - school $=10.34(0.035)$ ). It is not possible to talk about a significant difference for the other varia-

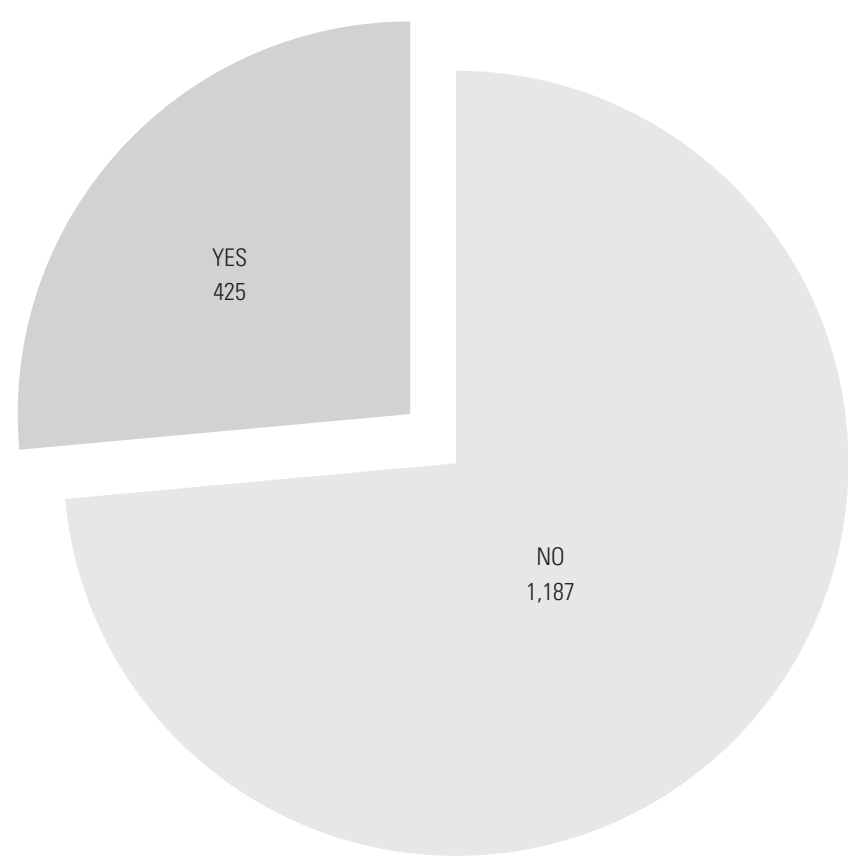

Have you smoked cigarettes (tobacco) in the last 3 months?

Figure 1 | Smoking in the last three months

bles. The distribution of variables, based on the residence of the respondents, is shown in Figure 2 and Figure 3.

When the differences in smoking by the categories of the variable 'Residence - home' were being interpreted (Figure 2), the emphasis was placed on the proportionality of individual categories of the selected variable. At first glance it is clear that it is not possible to talk about significant differences; it is indicated by the results of the $\mathrm{p}$-value, which was on the verge of confirming the difference $\left(\chi^{2}=8.04, p\right.$-value $\left.=0.045\right)$. The lowest number of respondents was from cities with a number of inhabitants from 100,001 to 1,000,000, followed by respondents from cities with a number of inhabitants up to 10,000 . The difference between the number of non-smoker respondents living in these city size categories is evident (city with a number of inhabitants from 100,001 to 1,000,000: $\mathrm{n}=81$; city with a number of inhabitants up to 10,000 : $n=139$ ), while the difference between the number of smokers is less obvious (city with a number of inhabitants from 100,001 to 1,000,000: $n=42$; city with a number of inhabitants up to 10,000: $n=48$ ). Another noticeable difference in the number of smokers and non-smokers when the respondents are compared according to their residence categories can be seen in the other two most numerous residence categories, where the difference between non-smokers is greater than the difference between smokers. As mentioned, the proportion between the number of respondents was not high and although the distribution of the places of residence of smokers and non-smokers is evaluated by the test as significant, the differences are not remarkable to such an extent that the smokers' and non-smokers' residence characteristics can be responsibly defined.

Figure 3 (similarly to Figure 2) shows the main differences in the proportion between the number of respondents by individual categories of the selected variable. It is obvious that 


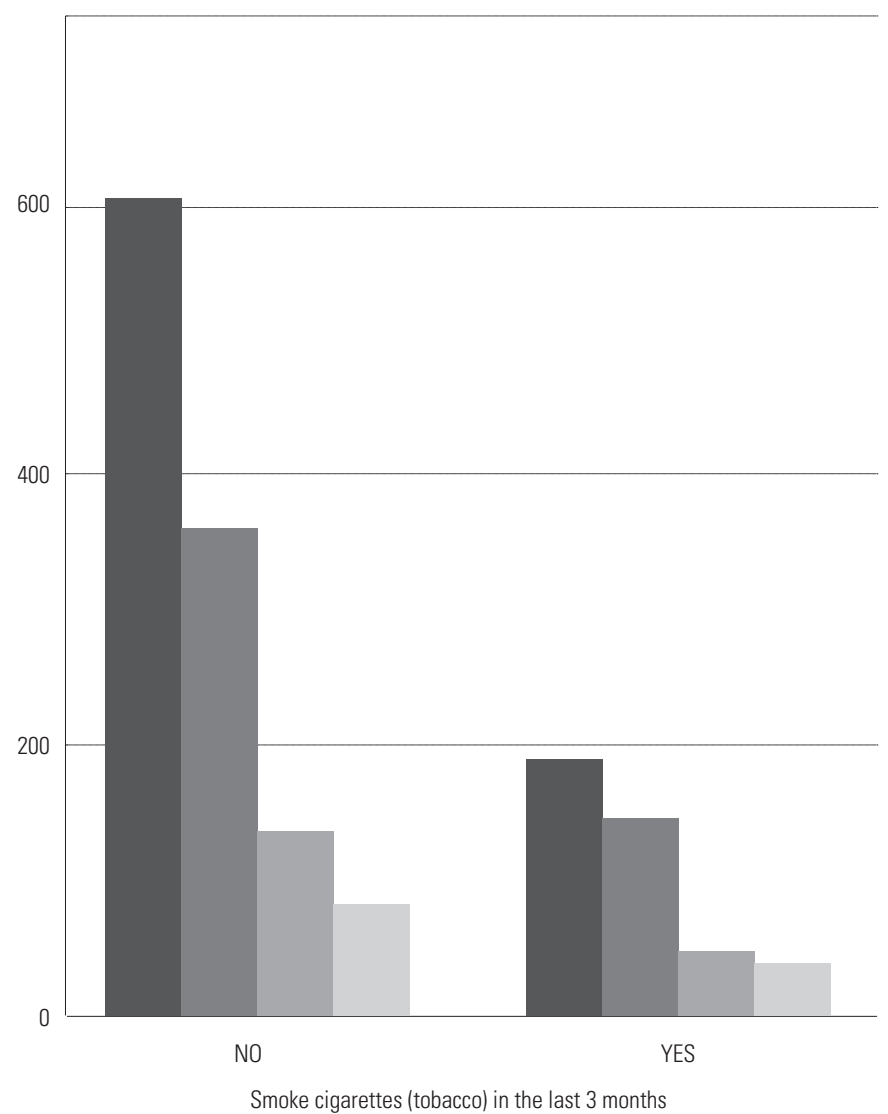

Residence - HOME

The countryside

City of 10,001 to 100,000 inhabitants
City with up to 10,000 inhabitants

City of 100,001 to $1,000,000$ inhabitants

Figure 2 | Distribution of variable 'Residence - home' by smoking

although the significance of the differences is confirmed $\left(\chi^{2}=10.34, p\right.$-value $\left.=0.035\right)$, these differences are of a visual nature only - not very significant.

Figure 4 shows the distribution of students who were smokers according to the intensity of their addiction. Mild Addiction was observed in more than a half of the cases $(n=234$; $55.06 \%$ ). The results in the category of Very Strong Addiction can be evaluated as satisfactory; only four respondents marked this eventuality (0.94\%). On the basis of this finding, it might appear that the level of behavioural dependence is relatively acceptable. However, on the one hand, there is no acceptable level of addiction for young people below productive age, and on the other hand, Strong ( $\mathrm{n}=$ 46; 10.82\%) and Moderate $(\mathrm{n}=141 ; 33.18 \%)$ Addictions indicate increased values. The process of determining the significance of the differences in the reported distribution between the selected variables follows. The Strong and Very Strong categories have been merged because of the low number of answers in the 'Very Strong' category.

Table 3 shows the output of testing for differences in the distributions between the selected variables. When the p-value is focused on, the value is not lower than 0.05 in any of the cases; this means that it is not possible to talk about signif-
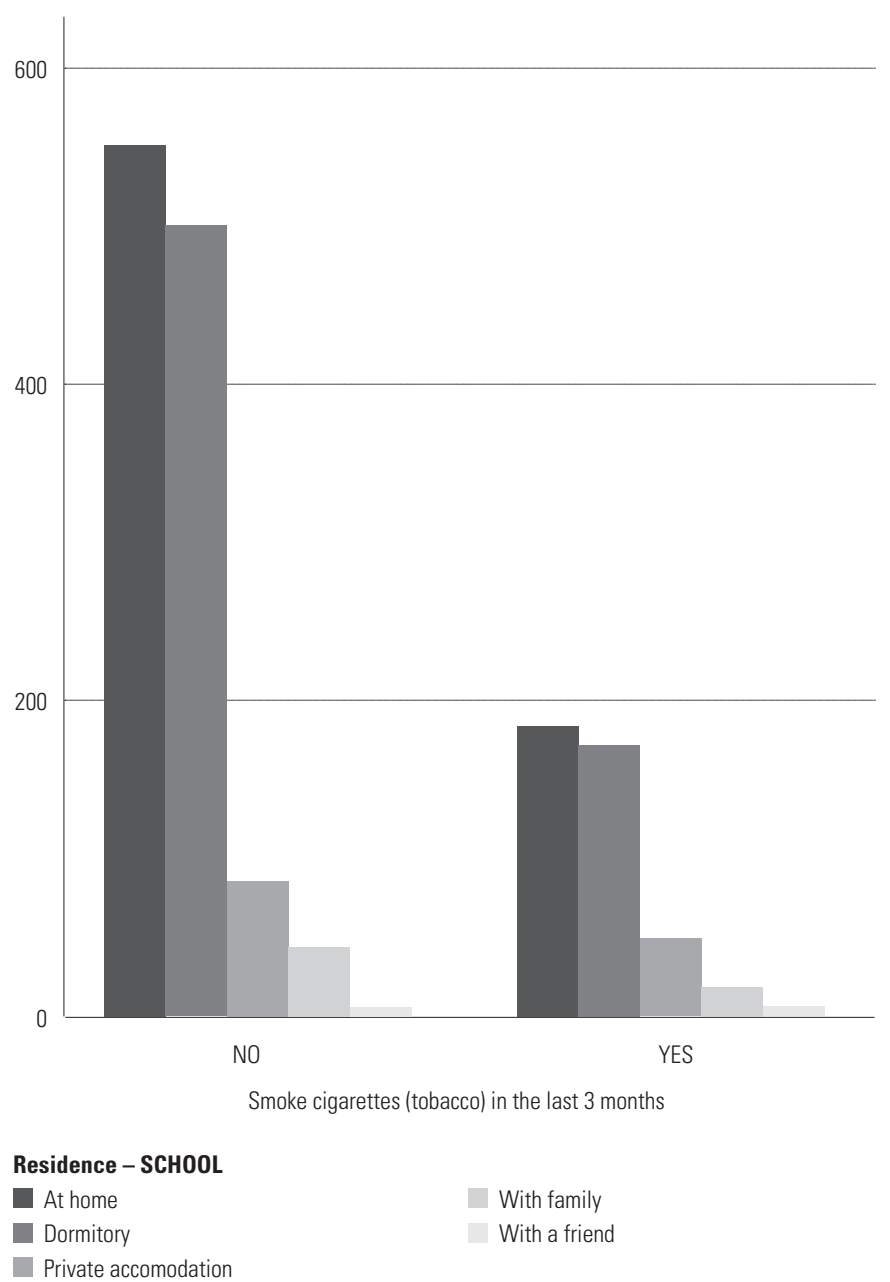

Figure $\mathbf{3}$ | Distribution of variable 'Residence - school' by smoking

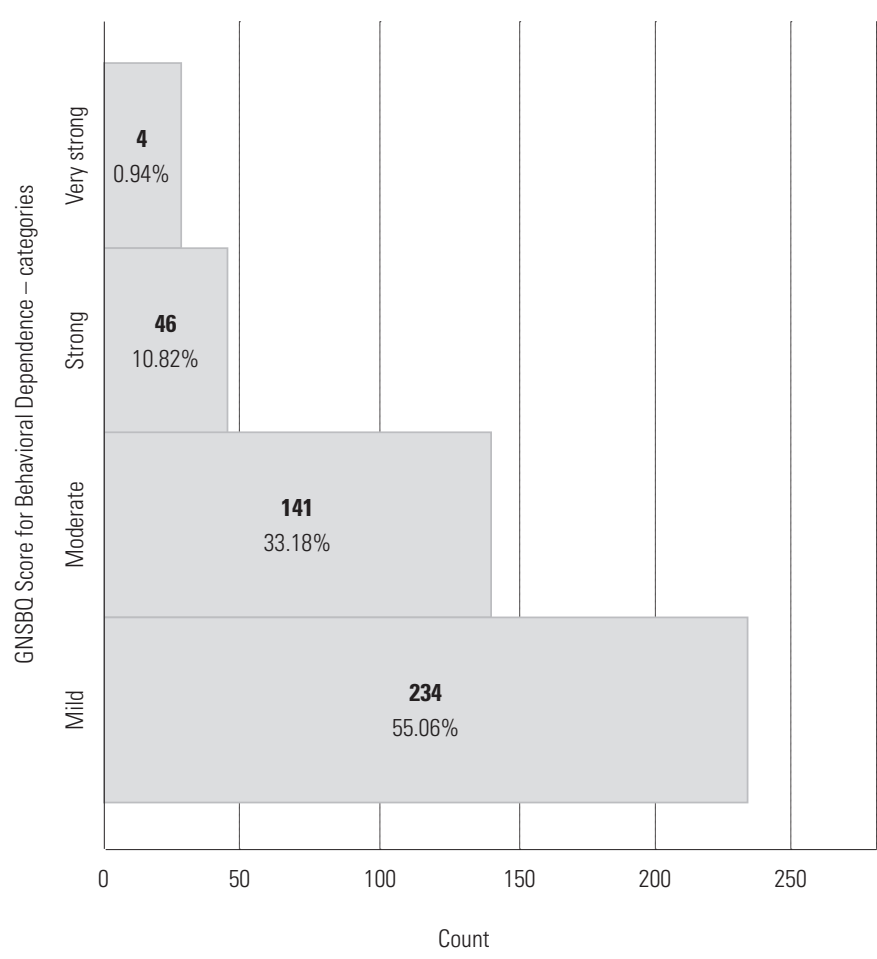

Figure 4 | GNSBO Categories 
icant differences in any of the cases. This can be perceived negatively e.g. in the Gender variable, as there is no difference in the intensity of addiction between the population of men and the population of women. Unfortunately, with the current trend, women will overtake men in terms of negative habits.

\begin{tabular}{lccc}
\hline Identification & $\mathbf{X}$ value & df & p-value \\
\hline Gender & 2.54 & 2 & 0.281 \\
\hline Degree of study & 8.19 & 6 & 0.225 \\
\hline Year of study & 14.95 & 10 & 0.134 \\
\hline Form of study: & 1.47 & 2 & 0.480 \\
\hline Residence - home & 6.06 & 6 & 0.417 \\
\hline Residence - school & 2.73 & 8 & 0.950 \\
\hline
\end{tabular}

Table $\mathbf{3}$ | Distribution test of GNSBO between selected variables

\section{DISCUSSION AND CONCLUSION}

Interconnecting the theoretical background with the results of the empirical part of the study makes it possible to compare the situation with regard to smoking behaviour among students in the Slovak Republic with the trends at the global level. The global trends indicate that smoking is still a leading cause of death and disease worldwide (Lawrence et al., 2013; Ng et al., 2014; Braillon, 2017; Wen et al., 2020). It is also a considerable cause of mental disorders (Kendler et al., 1993; Leventhal et al. 2011; Bakhshaie et al., 2015; Bainter et al., 2020; Weinberger et al., 2020). One of the riskiest periods of life in terms of acquiring smoking habits is the period of studying at university, when the individual (student) is most susceptible to the influences of society and social expectations or needs to compensate for social underestimation (Karadogan et al., 2018; Intarut et al., 2019; Leshargie et al., 2019; Wang et al., 2019; Azagba et al., 2020; Zhang et al., 2020).

The main objective of the study was to evaluate the incidence of smoking in the population of university students in the territory geographically determined by the Slovak Republic. This objective was achieved through several steps. In the first step, the segment of the population of students who smoke was defined. Subsequently, the smokers were divided on the basis of their Glover-Nilsson Smoking Behavioral Questionnaire (GNSBQ) score into groups of behaviour associated with smoking. Differential tests were also performed.

The survey showed that about two-thirds of the students are non-smokers (they stated that they had not smoked in the last three months). It was found that approximately $36 \%$ of the student population are smokers. On the evidence of the outputs of the $\chi^{2}$ test, the difference between smokers and non-smokers in the selected variables has been confirmed only in the cases of the following variables: Residence - home and Residence school. The surprising result is that it is not possible to say that men smoke more than women, because the difference has not been confirmed. The existence of differences between smokers and non-smokers regarding the size (category) of the city in which the student lives and regarding the type of accommo- dation he or she has when he or she is at university is statistically confirmed, but through a more specific assessment it has been found that there are no significant differences in the distribution that could fundamentally differentiate a smoker from a non-smoker. When smokers specifically are focused on, the fact that the largest group of smokers are smokers with Mild Addiction (55.06\%) can be assessed positively. This group of smokers is followed by a group of smokers with Moderate Addiction (33.16\%), then with Strong Addiction (10.82\%) and the fewest smokers belong to the group with Very Strong Addiction (0.94\%). The fact that the frequency of occurrence decreases with the increasing intensity of addiction can be evaluated positively. On the evidence of the selected variables (Gender, Degree of study, Year of study, Form of study, Residence - home, Residence - school) it is not possible to talk about significant differences in the intensity of addiction.

Health prevention and education continue to be very effective ways of eliminating smoking. One of the tools influencing the intensity of smoking is a change in taxes. It can be assumed that an increase in the tax burden would lead to the elimination of smoking among students. However, we place this idea only on the level of a hypothesis, which will be verified in further studies. At the same time, tobacco control policies should be more effective in anti-tobacco interventions and in promoting a healthy lifestyle for young people. Otherwise, smoking will continue to pose a health burden, as although this research study has shown that there are fewer smokers among students, the risk is still high, as their unhealthy habits also affect non-smokers, who will become passive smokers as a result. For this reason, public policy makers should be focused on this issue and consider it to be a major challenge that needs to be overcome.

The limitations of the research include the fact that the data was collected during the occurrence of the SARSCoV-2 virus. Despite this limitation, we consider the sample to be representative and valid. The ratio of smokers and non-smokers in the population mirrors the statistics for the entire society quite closely, but it is appropriate to perceive the different age of the respondents as a certain limitation, as not only full-time students but also part-time students were included in the sample (no substantial influence on the sample is expected). Future research will focus on assessing the significance of differences in the categories of variables other than those selected. It is also expected that the research will be expanded to other countries (V4 countries) and thus enable international comparisons of smoking. 
Acknowledgments: We thank the university students, without whom the research would not have been possible. We would also like to thank the university representatives, scientific, pedagogical, and administrative workers, who were very helpful in distributing the questionnaire.

Authors' contribution: Beáta Gavurová and Martin Rigelský designed the study and drew up the original draft of the manuscript. All the authors contributed to the data collection. Martin Rigelský performed the data processing and statistical analysis. Viera Ivanková and Martin Rigelský participated in the interpretation of the data and drawing conclusion. Viera Ivanková and Ladislav Suhányi conducted the literature review, summarized the related research and were responsible for drafting of the introduction to the article. Beata Gavurová and Viera Ivanková supervised the formal analysis and prepared the discussion. Martin Rigelský and Ladislav Suhányi were in charge of editing and visualization of the manuscript. All the authors contributed to the creation of the article equally and approved the final version of the manuscript.

Declaration of interest: No conflict of interest.

\section{REFERENCES}

Azagba, S., Manzione, L., Shan, L. P., \& King, J. (2020). Trends in smoking behaviors among US adolescent cigarette smokers. Pediatrics, 145(3)، e20193047. https://doi.org/10.1542/peds.2019-3047

Bainter, T., Selya, A. S., \& Oancea, S. C. (2020). A key indicator of nicotine dependence is associated with greater depression symptoms, after accounting for smoking behavior. Plos One, 15(5), e0233656 https://doi.org/10.1371/journal.pone.0233656

Bakhshaie, J., Zvolensky, M. J., \& Goodwin, R. D. (2015). Cigarette smoking and the onset and persistence of depression among adults in the United States: 1994-2005. Comprehensive Psychiatry, 60, 142-148. https://doi.org/10.1016/j.comppsych.2014.10.012

Berli, C., Ochsner, S., Stadler, G., Knoll, N., Hornung, R., \& Scholz, U. (2015). Volitional processesand daily smoking: Examining inter- and intraindividual associations around a quit attempt. Journal of Behavioral Medicine, 38, 306-317. https://doi.org/10.1007/s10865-014-9598-x

Braillon, A. (2017). Smoking is the first cause of morbidity and death in psychiatric settings. Canadian Medical Association Journal, 189(49), E1534-E1534. https://doi.org/10.1503/cmaj.733483

Branstetter, S. A., Muscat, J. E., \& Mercincacage, M. (2020). Time to first cigarette: a potential clinical screening tool for nicotine dependence. American Society of Addiction Medicine, Forthcoming. https://doi.org/10.1097/adm.0000000000000610

Doran, N., Spring, B., \& McChargue, D. (2007). Effect of impulsivity on craving and behavioural reactivity to smoking cues. Psychopharmacology, 194, 279-288. https://doi.org/10.1007/s00213-007-0832-x

Eurostat (2020), Tobacco consumption statistics. https://ec.europa.eu/eurostat/ statistics-explained/index.php/Tobacco_consumption_statistics

Fagerstrom K. (2003). Time to first cigarette; the best single indicator of tobacco dependence? Monaldi Archives for Chest Disease. 59 (1), 91-94. Available at: http://www.monaldi-archives.org/index.php/macd/index

Ferguson, S. G., Shiffman, S., Gitchell, J. G., Sembower, M. A., \& West, R. (2009). Unplanned quit attempts - results from a US sample of smokers and ex-smokers. Nicotine and Tobacco Research, 11(7), 827-832. https://doi.org/10.1093/ntr/ntp072

Foxon, F., \& Selya, A. S. (2020). Electronic cigarettes, nicotine use trends and use initiation ages among US adolescents from 1999 to 2018. Addiction. https://doi.org/10.1111/add.15099

Greden, J. F., \& Pomerleau, 0. (1995). Caffeine-related disorders and nicotinerelated disorders. In: Kaplan, H.I., Sadock, B.J. (Eds.), Comprehensive Textbook of Psychiatry, 6th edition, Williams \& Wilkins, Baltimore.

Intarut, N., Sangthong, R., \& Chongsuvivatwong, V. (2019). Smoking trends among Thailand's youths from 1996-2015: an age-period-cohort analysis of national health surveys. Iranian Journal of Public Health, 48(3). https://doi.org/10.18502/ijph.v48i3.885

Jayawardhana, J., Bolton, H. E., \& Gaughan, M. (2019). The association between school tobacco control policies and youth smoking behavior. International Journal of Behavioral Medicine. 26(6), 658-664.

https://doi.org/10.1007/s12529-019-09825-z
Karadogan, D., Onal, O., \& Kanbay, Y. (2018). Prevalence and determinants of smoking status among university students: Artvin Coruh University sample. Plos One, 13(12), e0200671. https://doi.org/10.1371/journal.pone.0200671

Kendler, K. S., Neale, M. C., MacLean, C. J., Heath, A. C., Eaves, L. J., \& Kessler, R. C. (1993). Smoking and major depression. A causal analysis. Archives of General Psychiatry, 50(1), 36-43. https://doi.org/10.1001/archpsyc.1993.01820130038007

Lawrence, D., Hancock, K. J., \& Kisely, S. (2013). The gap in life expectancy from preventable physical illness in psychiatric patients in Western Australia: retrospective analysis of population-based registers. BMJ, 346, f2539. https://doi.org/10.1136/bmj.f2539

Leshargie, C. T., Alebel, A., Kibret, G. D., Birhanu, M. Y., Mulugeta, H., Malloy, P., Wagnew, F., Ewunetie, A. A., Ketema, D. B., Aderaw, A., Assemie, M. A., Kassa, G. M., Petrucka, P., \& Arora, A. (2019). The impact of peer pressure on cigarette smoking among high school and university students in Ethiopia: a systemic review and meta-analysis. Plos One, 14(10), e0222572. https://doi.org/10.1371/journal.pone.0222572

Leventhal, A. M., Zvolensky, M. J., \& Schmidt, N. B. (2011). Smoking-related correlates of depressive symptom dimensions in treatment-seeking smokers. Nicotine \& Tobacco Research, 13(8), 668-676. https://doi.org/10.1093/ntr/ntr056

Ng, M., Freeman, M. K., Fleming, T. D., Robinson, M., Dwyer-Lindgren, L., Thomson, B., \& Murray, C. J. (2014). Smoking prevalence and cigarette consumption in 187 countries, 1980-2012. JAMA, 311(2), 183-192. https://doi.org/10.1001/jama.2013.284692

Septiono, W., Kuipers, M. A. G., Ng, N., \& Kunst, A. E. (2020). The impact of local smoke-free policies on smoking behaviour among adults in Indonesia: a quasi-experimental national study. Addiction. https://doi.org/10.1111/add.15110

Shiffman, S., Balabanis, M. H., Gwaltney, C. J., Paty, J. A., Gnys, M., Kassel, J. D., \& Paton, S. M. (2007). Prediction of lapse from associations between smoking and situational antecedents assessed by ecological momentary assessment. Drug and Alcohol Dependence, 91, 159-168. https://doi.org/10.1016/j.drugalcdep.2007.05.017

Shiffman, S., Waters, A., \& Hickcox, M. (2004). The nicotine dependence syndrome scale: a multidimensional measure of nicotine dependence. Nicotine \& Tobacco Research, 6(2), 327-348. https://doi.org/10.1080/1462220042000202481

Wang, T. W., Gentzke, A. S., Creamer, M. R., Cullen, K. A., Holder-Hayes, E., Sawdey, M. D., Anic, G. M., Portnoy, D. B., Hu, S., Homa, D. M., Jamal, A., \& Neff, L. J. (2019). Tobacco product use and associated factors among middle and high school students - United States, 2019. MMWR Surveillance Summaries, 68(12), 1-22. https://doi.org/10.15585/mmwr.ss6812a1

Weinberger, A. H., Chaiton, M. O., Zhu, J. O., Wall, M. M., Hasin, D. S., \& Goodwin, R. D. (2020). Trends in the prevalence of current, daily, and nondaily cigarette smoking and quit ratios by depression status in the US: 2005-2017. American Journal of Preventive Medicine, 58(5) https://doi.org/10.1016/j.amepre.2019.12.023 
Wen, H., Xie, C., Wang, F., Wu, Y., \& Yu, C. (2020). Trends in disease burden attributable to tobacco in China, 1990-2017: findings from the Global Burden of Disease Study 2017. Frontiers in Public Health, 8, 237.

https://doi.org/10.3389/fpubh.2020.00237

World Bank (2020). Smoking prevalence - Slovak Republic

https://data.worldbank.org/indicator/SH.PRV.SMOK.FE?locations=SK

Yuan, M., Guo, X., Li, X., Chen, X., Wang, C., \& Li, Y. (2018). The moderating role of regulatory emotional self-efficacy on smoking craving: an ecological momentary assessment study. PsyCh Journal, 7(1), 5-12.

https://doi.org/10.1002/pchj.188

Zeuske, M. (2016). Slaves and tobacco in the Atlantic World History (Sklaven und tabak in der atlantischen Weltgeschichte). Historische Zeitschrift, 303(2). https://doi.org/10.1515/hzhz-2016-0379

Zhang, C. L., Xu, Y. M., \& Zhong, B. L. (2020). The association between smoking and loneliness among Chinese university freshmen. Annals of Translational Medicine, 8(10). http://dx.doi.org/10.21037/atm-20-3523

Zhou, X., Crippa, A., Danielsson, A. K., \& Galanti, M. R., Orsini, N. (2019). Effect of tobacco control policies on the Swedish smoking quitline using intervention time-series analysis. BMJ Open, 9(12), e033650.

https://doi.org/10.1136/bmjopen-2019-033650 